Bol. Acad. peru. leng. 48. 2009 (115-124)

\title{
ENTONACIÓN Y SINTAXIS (I)
}

\author{
Luis Jaime Cisneros Vizquerra
}

Academia Peruana de la Lengua

Fecha de recepción:

$20 / 08 / 2009$

Fecha de aceptación:

$10 / 10 / 2009$

Antes de iniciar la visa escolar, y antes ciertamente de sus primeras clases de gramática, las criaturas han descubierto provechosamente en la vida familiar los valores significativos del silencio y de la entonación. La escuela ha permanecido, y permanece, desinteresada de esta realidad, empeñada en preocuparse por la preceptiva gramatical. En la casa, sin embargo, el futuro escolar ha confirmado que los mayores conocen y valoran las modulaciones fónicas y los silencios voluntarios, a cuyo rigor y usufructo suelen convocarlos los menores. ${ }^{1}$ Los ejemplos son numerosos: "A mí no puedes hablarme en ese tono”, “Baja la voz!”, “¿Cómo te atreves a levantarme la voz?". Y testimonian que en el hogar se conoce el significado de estas modulaciones vocales. Lo mismo ocurre con el otro tipo de ejemplos: "¿Qué te pasa, criatura, que estás tan callado?”, “¿Por qué no contestas?”, “Acaso no oyes que estoy hablando contigo?” son ejemplos que expresan sorpresa frente la cauteloso y meditado silecio

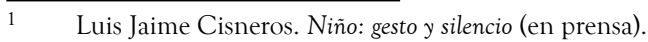


con que las criaturas 'castigan' y 'miden' a sus mayores. “¡Ya no soy tu hijo!" suele dar por terminada una conversación y puede resultar anticipo verbal del mutismo con que la critura se defiende y nos reta frente a tanta pregunta nuestra. El silencio expresa, así, la contrariedad del muchacho. Los silencios también significan.

Todo esos e ofrece como interesante ocasión para reflexionar en un curso universitario que busca interiorizarse de los secretos del lenguaje. Porque todo esto anuncia que, en el proceso de adquisición del lenguaje, el niño está muy atento al entorno. La situación idiomática (de la que la criatura probablemente nunca oirá hablar) integra el contexto de la comunicación. El lenguaje se adquiere en diversas y disímiles situaciones concretas en las que las frases (ya no las palabras) vienen acunadas en determinados tonos de voz y expresan -a través de modulaciones ascendentes o descendentes- estados de ánimo diversos (a veces acompañados de gestos) de que se vale el emisor para robustecer su estado emocional, o para enfatizar su voluntad personal, o para precisar su grado de interés; los distintos matices, en fin, de su participación afectiva en el discurso. Son rasgos que sirven, por lo tanto, para que el oyente vaya tomando nota de la intención con que las cosas se comunican. Esa es información callada y valiosa para el niño. Es un oyente que no vive rodeado por gente que avienta palabra sino que expresa oralmente, a través de frases, sus opiniones y deseos envueltos en moldes y revelan simultáneamente el estado de ánimo, su afán de aconsejar, sus deseos, sus órdenes, sus apreciaciones ingenuas o severas. "Pásame la cuchara, por fa...”, ¡Qué hora tienes?", "Pásale esto a tu tío”, "Mira bien lo que haces”. "No pongas los codos sobre la mesa", "Suénate sin hacer ruido". A veces hemos oído, y sabemos que no es pregunta en realidad: "¿Por qué no me convidas un pedacito de tu helado?", "¡Tanta torta te comiste, granuja?" "QQué bien te queda esa bufanda, abuelo!”.

Aunque la escuela no le ha otorgado merecida atención, la entonación no ha sido tema ignorado por los lingüistas. El campo ideal de observación ha sido siempre la frase, porque de ella nos valemos para expresarnos y porque de ella nos servimos en la comunicación diaria. Y como no es un fenómeno que afecta a la palabra, puesto que dependen 
de la situación en que se halle el discurso, el campo de la sintaxis se ofrece como el más propicio para la reflexión.

Lo primero que conviene puntualizar es que el español es lengua de modulación paroxítona, a diferencia del francés, que es oxítona (Cf. Mariposa, papillon; trabajo, travail). Basta con abrir un periódico y comprobar que si tuviéramos que acentuar gráficamente todas nuestras palabras paroxítonas, nos asombraría la enorma mancha obtenida.

2. Esta vinculación entre entonación y sintaxis la puso de relieve, hace más de medio siglo, Charles Bally en un célebre trabajo titulado Intonation et syntaxe (CFS, I, 1942, 33-41). La primera afirmación fue reconocer que entonación pausas y melodía eran valores fundamentales de todo idioma bien constituido. Ya lo había anticipado Bally en su Traité de Sytlistique $(1969$ ? ) y era un tema sobre el que el que años atrás habían anticipado opinión el danés Andréas Blinkenberg (1928-1933) y el alemán Eugen Lerch (1934). ${ }^{2}$

Para ingresar en el tema, necesitamos distinguir entre acento de intensidad y melodía. Claro es que uno y otro son concurrentes en todo esquema sintáctico, pero no son (lo afirma Bally) necesariamente solidarios. Un ejemplo servirá para aclararlo:

a) Este hombre, ¡Yo lo conozco!"

b) "Yo conozco a este hombre"

Hombre tiene el mismo acento en una y otra frase; pero la melodía del sintagma este hombre no es la misma: es ascendente en un caso, y descendente en el otro. Bally nos invita a precisar lo que escuelta musicalmente determinante para la fijación de un tipo sintáctico". Eso obliga a precisar los dominantes acentúales y los dominantes melódicos. Y nos invita a confrontar el ejemplo alemán: Du bist schuldig "Tú eres culpable". Me bastaría, en español, ir distribuyendo la intensidad acentual

$2 \quad$ Blikenberg. L'orde des mots en français moderne; Eugen Lerch, Französische historische Syntox Vol. III Modälitat (Leipzig, 1931).

Bol. Acad. peru. leng. 48(48), 2009 
para enfatizar la afirmación pronominal o las voces alusivas a verbo o adjetivo. En cambio, en el siguiente ejemplo deberemos recurrir a la dominancia melódica:

a) “No se puede fumar, acá?"

b) “No se puede fumar acá?"

Aquí, a pesar de que la palabra final es la acentuada, la pausa, (y sobre todo la caída de la voz sobre acá) da a la curva melódica su estricto valor.

Asunto que también merece atención es el relacionado con las pauses mdias, Bally advierte que, en francés, la presencia o la ausencia pueden ofrecernos dos tipos sintácticos diferentes:

a) Me quedo en casa, porque hace frio"

b) Me quedo en casa, porque hace frío"

Aquí, la lengua se pone al habla, y la fonología a la fonética (Bally, 35) Pero las pausas existen "sin que el hablante pierda conciencia de su realidad latente". El texto de Bally es interesante:

a) Au milieu du parc il y a un bassin"

b) Au mileu du parc se trouve un bassin"

En b) podemos comprobar que l'inversion du sujet est incompatible aved la pause; c'est/dans a) il y a un bassin est une phrase / que grammaticalement complete et indépendante, ce qui n'est pas le cas pour se trouve un Bassin" (Bally, 35) Esto obliga a tener mucho cuidado con la puntuación. Veamos los dos ejemplos:

a) "Hace frío: no saldremos hoy"

b) "No saldremos hoy. Hace frío"

La melodía marca la subordinación. En la sintaxis emotiva, la melodía resulta decisiva: "si un elemento comporta una pronunciación 
exclamativa, es necesariamente autónomo, y por lo tanto, está coordinado con lo que lo precede o lo sigue". En los recientes ejemplos, a) expresa la consecuencia del frío: no saldremos. En el caso de b) hace frío expresa la causa. Nuevos ejemplos nos alertarán:

a) ¿El granuja se ha llevado todo!

b) Se ha llevado todo. ¡el granuja!

Para segmentar la frase, suprimo la exclamación: "Se ha llevado el granuja Hay que estar atentos a la importancia que cabe asignar a la media pausa (pause médiale, la llama Bally, 38) Esa pausa en nuestros últimos ejemplos nos permite anunciar que "els segmento A no es complemento del segmento Z, representado a menudo por un pronombre":

a) "Ese individuo, no lo conozco"

Distinto es el sentido (y diversa la intención) en los casos siguientes:

a) "Aquí no se fuma"

b) "No se fuma, aquí"

c) "No se fuma aqui"

En una de las frases entendemos que en otros lugares se puede fumar: podemos pensar en un restaurant, en un tren. Si reparamos, podemos descubrir que la advertencia, en lengua oral, puede venir acompañada de un gesto acompañante para aquí. Para privar a la advertencia de tono autoritario, hay instituciones que han optado por otro tipo de aclaración: "salón para fumadores", "sector de fumadores" Convendría deternernos en otro caso, y dejar bien establecido lo concerniente a la pausa medial:

a) Este perro, le hace falta entrenamiento"

Si nos atenemos a una rápida y ligera observación, diríamos (aunque no se percibe fácilmente) que este perro es un complemento verbal; le es, en verdad, el que asume esa función. Lo advertimos en la frase segmentada: 
b) "A este perro le hace falta entrenamiento"

Estas distinciones son importantes, y necesitan explicación sobre todo si queremos asumir los casos de subordinación y de frase ligada. Puede darse (y Bally lo ejemplifica) que Z sea una segmental (az/za): en este caso pausa y entonación asumen "el máximo de su valor representativo". Confrontemos los ejemplos, español y francés:

a) Este hombre, yo, no lo conozco Para explicar la frase recurriríamos, en lo relativo al pronombre, "Lo que es yo". De donde el grupo AZ $(\mathrm{Z}=\mathrm{az})$. Resultaría menos enfático que el ejemplo francés "Moi, je ne le connais pas". Distinta situación se ofrece en:

b) Este hombre, no lo conozco

en que $\mathrm{AZ}(\mathrm{Z}=\mathrm{za})$ Consideramos el ejemplo propuesto por Bally (ibid., 39) donde una misma frase nos permite enfrentar tres tipos de desarrollo: Traduzco el ejemplo:

c) "Esta construcción sintáctica es muy frecuente en latín"

¿Por qué considera Bally tres tipos de pronunciación? He aquí su explicación:

1) "en latín puede separarse de lo que precede mediante pausa y "asumir una entonación autónoma explicativa”. Estaríamos diciendo: "agrego que esta frecuencia concierne la latín”. Sería un itpo Zz)

2) "Il peut, tout en comportant une pause, se prononcer sur un ton bas; il deviene alors le thème (retardé) de ce qui précède (type ZA);

3) Puede - por último- darse in pausa medial, y sin entoncación particular: "faire partie d'une phrase liée, oú le thème et le propos -répétons-le- sont déterminés uniquement par le contexte de la situation". 
Aclaremos, a propósito de esta tercera interpretación, y volviendo al texto original:

a) "Cette construction est très fréquente en latin"

En un gramática Latina (Bally lo afirma) "frequente será el objetivo del enunciado. Pero si la frase en un tratado donde se comparasen varias lenguas, el objetivo sería en latín".

3. Interesa ahora considerar algunos casos. Veamos tres modelos:
a) "Aquí. Siéntese usted"
Z
b) Siéntese usted. Aquí
$Z^{\prime}$
c) Siéntese usted aquí
Z"

En el ejemplo a) anunciamos la intención con que el emisor se ha visto necesitado de precisar aquí. En el segundo caso, se señala el sitio que debe ocupar el oyente. En el tercer ejemplo las intenciones del emisor brillan por su ausencia. Bally explica así los dos primeros casos:

Or, chaque coordonnée a une intonation autonome, correlative à son independance grammaticale et à son modalité. La pause est en general bien nette, mais, comme toujours dans la parole, elle peutëtre abrégée et meme supprimée, d'oú l'illusion qu'on a affaire à la segmentation ou à la phrase liée; c'est alor que la mélodie remet la chose au point. La méconnaissance de ce critère est une source d' erreurs, et la confusion est particulièrement fréquente entre coordination et segmentation" (ibid., 39)

4. Puede ocurrir que una frase se vea partida en dos por un elemento intercalado (un incidente o un inciso) / El caso nos interesa "car l'incise relève sois de la coordination sois de la segmentation" (ibid., 40). Veamos estos ejemplos:

a) "María Luisa -y fue una suerte- abandonó la idea de viajar"

b) "Tiene usted (lo estoy viendo) un hermoso jardín"

Bol. Acad. peru. leng. 48(48), 2009 
No siempre es fácil establecer el orden lógico en este tipo de frases. En a), la conjunción / y / anuncia que el inciso es 'una coordinada anticipada'. Otro es el caso b).

c) Tiene un hermoso jardín. Lo estoy viendo"

No interesa acá el orden lógico. Bally es terminante al respecto:

'L' essentiel est que l'intonation montre que ces incises sont indépendantes de la phrase enveloppante, car cette intonation est celle que les parties intercalées auraient bien les détachait de leer contexte" (ibid., 40)

Bally invita seguidamente a considerar todo inciso exclamativo como una frase. Podríamos considerar dos tipos:

a) "Ha abusado -iAh, el infeliz!-, de mi ignoracia"

b) Se ha dedicado -el infeliz- a burlarse de todo el mundo

En este último ejemplo advertimos que el tono exclamatorio se ha transformado en un tono estrictamente convencional.

5. Todas las observaciones que nos han ocupado hasta ahora ponen de relieve, por cierto, la diferencia entre frase y elemento de frase. Bally aclara:

"Ce qui définit la phrase, c'est, pour le signifié, ls mofslité, c'est à dire, l'atttitude subjectif du parleur vis-àa-vis de ses répresentations objectives, et, pour le signifiant, l'intonation autonome, reflet directe de la mofalité". ${ }^{3}$

Claro se está: las variantes de entonación son tan numerosas como las modalidades que puede ofrecernos el discurso: afirmaciones, exclamaciones, interrogación es, órdenes, deseos, recriminaciones,

3 Linguistique générale et linguistique française (Berne, Francke, 1944) 
lamentos, "aparte de las múltiples insinuaciones emotivas que acompañan a las formas fundamentales". Para que una frase se convierta en elemento frásico, dice Bally:

"il faut (et souvent il suffit) que la modalité en sois absente, et, parallèlement, que son intonation cesse d'ëtre autonome".

Para concluir, hé aquí tres frases:

a) Gabriel está quebrado.

b) Que Gabriel esté quebrado, no lo dudo.

c) Yo no dudo de que Gabriel esté quebrado.

La frase a), donde la modalidad implícita se halla confiada al indicativo, es autónoma tanto desde el punto de vista melódico, como desde el gramatical: es decir, por modalidad y por entonación. Y ésta podría variar "según la naturaleza de los movimientos subjetivos que hayan originado el enunciado". La frase b) ofrece una estructura $\mathrm{Az}, \mathrm{La}$ modalidad está confiada a un verbo modal (dudar), que, segura al fragmento Z su autonomía y le permite, según Bally, "variables de entonación, según el caso. La idea de la quiebra se ha convertido en el dictum:

"el miembro de frase que la contiene es el tema del enunciado, y, como consecuencia, función de $\mathrm{Z}$, de donde la pérdida de la autonomía gramatical. Privado de todo valor modal propiamente dicho, se ha convertido en un instrumento de transposición de una principal en subordinada, al mismo tiempo que ha perdido autonomía melódica. La entonación, uniforme, estereotipada, se vuelve incapaz de variaciones apreciables" (Bally, LGLF, 42)

La frase c) es un bloque sintáctico y melódico: "la subordonée n’a plus trace d'intonation propre". 


\section{Correspondencia:}

\section{Luis Jaime Cisneros Vizquerra}

Miembro de Número de la Academia Peruana de la Lengua.

Correo electrónico: academiaperuanadelalengua@yahoo.com 